\title{
Towards Innovation Competences: a Finnish Perspective
}

\author{
Harri Lappalainen \\ Faculty of Engineering and Bussiness \\ Turku University of Applied Sciences \\ Turku, Finland \\ harri.lappalainen@turkuamk.fi
}

\begin{abstract}
The Fourth Industrial Revolution has understandably strengthened the importance of digital skills as key competence area that should be enhanced during all grades of studies. Additionally, generic competences enabling successful participation in innovation processes are very much highlighted by employers worldwide. This sets challenges to the ways we educate next generations. We need changes in all main stages of education: planning, implementation and assessing learning outcomes. When targeting to increase students' innovation capacity, is there something we could learn from recent European, especially Finnish, strategic definitions of policies and development novelties?
\end{abstract}

Keywords - innovation pedagogy, innovation competences, lifelong learning, Finnish new national curriculum, constructive alignment in education

\section{INTRODUCTION AND FRAMEWORK}

According to a 2016 survey by the World Economic Forum [1], employers rank complex problem solving, critical thinking and creativity as top three skills in 2020. Alike findings and results have been provided by several other international and national surveys, even when the target year is one or two more decades in the future. Industrialization 4.0 was launched publicly around two years ago and it has been followed by the Education 4.0 where the skills needs are very much in line with the World Economic Forum report's observations.

Above mentioned top three skills are all linked on creating new innovations to serve the purposes of citizens, organizations or the whole society. In 2011, Turku University of Applied Sciences (TUAS) from Finland with its European partners started to make practice-oriented research on defining essentials of innovation capacity of individuals. Main research challenge was to define the skills, knowledge and attitudes needed for innovative behavior.

Based on several years' systematic European-wide research and development actions, five core dimensions of innovation competences have been defined: Initiative (ability to make decisions or carry out actions to operationalize your ideas as well as mobilize and manage those who have to implement the ideas); Creativity (ability to think beyond tradition to generate or adapt meaningful alternatives); Critical Thinking (ability to deconstruct and analyze ideas); Team work (ability to work efficiently with others in a group); Networking (ability to involve internal/external stakeholders). This FINCODA (Framework for Innovation Competences Development and Assessment) model has been psychometrically validated in the University-business cooperation environment and the mixed-method validation study - conducted by the experts from the Utrecht University of Applied Sciences - showed that relevant innovation process competencies can be measured in an adequate manner [2].

John Biggs [3] speaks about constructive alignment in education. Constructive learning process means that students are given the opportunity to find meaning through learning activities. The teacher has a role as a facilitator in the learning process, the teacher provides an environment that allows students to find meaning in the learning process. Biggs also summarizes three main operative steps towards a successful learning as follows: 1) Defining the intended learning outcomes; 2) Choosing teaching/learning activities likely to lead to the defined learning outcomes; 3) Assessing students' actual learning outcomes to see how well they match what was intended. Biggs' Constructive Alignment model is a good framework also to discuss about reforming educational structures and practices to enable the effective enhancement of students' innovation competences.

My intention in this paper is to provide some experiences and insights on enhancing and assessing students' innovation competences in different educational levels, based on my 20 years' development work mainly in Europe and South-East Asia.

\section{INNOVATION COMPETENCES IN STRATEGIES}

Adopting a 21st Century Curriculum is one of the main priority areas in the future vision, presented by the Southeast Asian Ministers of Education Organization SEAMEO [4]. Alike visions and plans exist also widely in Europe in different education levels. In Europe, all European Union countries are responsible for their own education and training systems. The role of EU is to support national actions and help to address common European challenges. Education and Training 2020 (ET 2020) strategy [5] is the framework for cooperation in education and training and educational-level specific strategies complement it. Focusing on Innovation Competences is a rather new theme in European level strategies and it hasn't had mentionable position in the list of Key Competences. However, in the latest Council Recommendation on Key Competences for Lifelong Learning which was adopted on May 2018[6], creativity as well as initiative and innovation are mentioned under entrepreneurship and STEM (Science, Technology, Engineering, Math) themes. Additionally, for the first time these themes have a strong position e.g. in the 2017 launched new EU Agenda for Higher Education [7]. Notable in that new HE strategy is also the encouragement for the cooperation between $\mathrm{HE}$ institutions and all other school levels, this represents kind of "lessons learned" for all actors and not only for HE providers. 
Innovation competences can have a strong position also in organizational level strategies. We in Turku University of Applied Sciences have been discussing for several years about the necessity and ways to enhance students' innovation competences, see e.g. a book from year 2013 "Pedagogical Views on Innovation Competences and Entrepreneurship" [8]. Additionally, our University launched a new strategy in 2015 where we defined Innovation Pedagogy an official joint learning approach of the whole University. Multidisciplinary learning environments, working life orientation and flexible curricula are essential requirements for innovation pedagogy to succeed. Entrepreneurship and entrepreneurial attitude are emphasised and internationalization is embedded into studies in versatile ways. Our main goal is that all our graduates should be able to participate in diverse innovation processes and for that they need innovation competences. Fivedimension FINCODA model guides our University's staff in all stages of the education from curriculum planning until the assessment of students' learning outcomes.

\section{NEW ERA IN THE FINNISH BASIC EDUCATION}

When speaking about primary education, the first Programme for International Student Assessment (PISA) was conducted in 2000 and Finland has been succeeding in PISA really well from the very beginning. Dr. Pasi Sahlberg presented thoroughly the secrets of Finnish education system in his Finnish Lessons [9] and Finnish Lessons 2.0 books. "Why to fix something that is not broken?" is an often-heard question when speaking about needs and necessity to renew Finnish educational system. A very good generic illustration of main needs to move towards new era in education has been done by Sir Ken Robinson [10]. In Finland, we have realized that the world is changing really rapidly and the school system that was developed in and for the industrialized era is nowadays inappropriate when speaking about future needs for skills and knowledge.

We need forward-looking and adaptable strategies but when going into implementation of the education, there are only two key players: the main enabler (teacher) and the learner (student). In Finland, teacher is a very appreciated profession and basically all teachers in all educational levels hold at least Master's degree. Additionally, teachers have a lot of freedom and trust. According to the results from TALIS 2013, the global wide survey on teachers and conducted by OECD, Finnish teachers are mainly assessed in annual discussions with their Principals or Rectors and most often these discussions are forward looking rather than evaluating their past performance or results [11]. In Finland, best teaching and learning practices are shared with teachers and included in the learning culture of the school, this makes formal national assessment of teachers mainly unnecessary.

Finland has recently launched a new national core curriculum for basic education in stages: grades 1-6 started implementation already in 2016 and after that one grade per year has joined to this reform so that 9th grade will adopt it in 2019. In Finland, municipalities are responsible for basic education and together with schools they have made local curricula which is based on the new national curricula. Under the following headings, I will shortly describe the main reforms in Finnish basic education, presented in details in the Finnish National Core Curriculum for Basic Education [12].

\section{A. Renewing Subjects}

In the new curricula for Finnish basic education, there are still 20 subjects to be studied. Earlier these subjects were separated from each other's so that all subjects had their individual plans. From the perspective of learner, this is or was too often studying without clear understanding on the relation of the topic to the real world. The new curriculum is often titled as a "phenomenon-based curriculum". In practice, it means that objectives and content of the subjects have been updated to better reflect today's and tomorrows' society as well as competences needed in the future. Additionally, real-life problems can be taught and learned simultaneously in several subjects; e.g. planting a seed and enabling a plant growth may give great learning objects to numerous subjects. This kind of holistic learning is put in practice in order to increase the pupils' interest and motivation towards learning and increase the intended learning outcomes.

\section{B. Transversal Competences}

There are 7 different transversal competences that are taught, studied and assessed as part of every subject: 1) Thinking and learning to learn; 2) Cultural competence, interaction and self-expression; 3) Taking care of oneself and managing daily life; 4) Multiliteracy; 5) ICT competence; 6) Working life competence and entrepreneurship; 7) Participation, involvement and building a sustainable future. Recognition of these competences as official learning objectives set positive pressure to teachers to organize their classes in adequate and diverse ways.

\section{Changing the Ways Schools Operate}

The leading principle is to see the school - and all actors from teachers and other staff of the school until pupils - as a learning community. Schools must provide enough opportunities for experimentation, exploration, active learning, physical activity and play. In Finland, the number of migrants is increasing and the use of various languages in the school's daily life is seen as natural, and languages are appreciated. This year 2018, the Finnish National Government has decided that starting from year 2020 all Finnish pupils will begin to learn first foreign language already from the first school year, now it starts in the beginning of 3rd grade.

There is a strong an aim to ensure the well-being and safety of every pupil. During recent years', there have been government-funded interventions to develop schools to tackle existing problems. KiVa is an innovative evidencebased antibullying program to prevent bullying and to tackle the cases of bullying effectively [13]. In Finland, most of all comprehensive schools in the country are registered as $\mathrm{KiVa}$ schools and are implementing the program. Global wide, $\mathrm{KiVa}$ has licensed partners in more than 10 countries. KiVa has three units; Unit 1 is designed for children of 6-9 years of age; Unit 2 is suitable for children of 10-12 years of age; Unit 3 is meant to be used after the middle school/lower secondary school transition, for students of around 13-16 years of age. 


\section{At Least One Multidisciplinary Learning Module A Year}

Teachers, together with pupils, plan at least one multidisciplinary learning module per year for their class. These modules have clear and well-defined theme which can arise from the local needs. Real-life cases are learned from the perspective of several subjects. Schools/teachers may decide technical aspects, like the duration, by themselves.

\section{E. Diversity in Pupil Assessment}

The new national curriculum emphasizes diversity in assessment methods. Furthermore, assessment should promote and deepen learning. Assessment should also be transparent to all key actors, including pupils and their parents.

As a unique character, Finnish education system is lack of standardized testing which would cover all pupils or students in certain grade. Actually, there is only one standardized test for all and it is the matriculation exam which is organized in the last year on upper secondary school (grade 12 when students are at the age of 17-18). Before that, only some referential national exams are organized which results are not official and are not used as an administrative tool in national neither local level.

\section{ASSESSING INNOVATION COMPETENCES}

Like Biggs' presented, the assessment of learning outcomes should be in line with the aims and implementation of studies. As learned from the FINCODA five-dimension model, in addition to personal level competences, successful participation in innovation processes often require competences to work in social contexts, i.e. in teams or wider networks. Therefore, the assessment of one's innovation competences must be behaviour-based and conducted by person(s) who can observe one's performance in adequate settings. This is often a real challenge for educational organizations with lack of observation resources (one teacher/tens of students) and strong tendency to utilize only written exams.

In TUAS, we also found this issue very challenging when started to conceptualize our aims and define the assessment practices for innovation competences [14]. After the desk research, conducted in 2011, we could not find any appropriate tools for assessing innovation competences and as a logical consequence, we started to develop the own tool for this purpose. Our first publicly released innovation competences assessment tool was an INCODE Barometer [15]. Systematic work continued and finally, after several years' international development and research work, we managed to launch a psychometrically validated tool for assessing innovation competences. This FINCODA Barometer Innovation Assessment Tool (later FINCODA Barometer) can be used to assess individuals' innovation competences in different settings: in educational organizations (as applied even in primary education), in companies as well as in public sector organizations. It can be used as a self-assessment or peer-assessment (students assessing each other's) tool and teachers can use it according to their own needs. So far, we have good experiences in using peer assessment, especially from higher education context, but it would be valuable to receive any kind of user experiences of the FINCODA Barometer also from the other school levels.

To enable the smooth use of the FINCODA Barometer, we have now provided an FINCODA Software Application. This FINCODA SA is an online tool which can be used with several devices (computer, laptop, tablet, smartphone) to measure and illustrate students' innovation capacity. The results will be provided in graphs and tables and supported with recommendations for the future. The use of the FINCODA Barometer is based on action or behaviour assessment. Therefore, we have also provided a Rater Training Toolkit to boost users' skills in assessing innovation behaviour. All these FINCODA materials and outputs can be found as free Open Educational Resources from the FINCODA website [16]. FINCODA model has been acknowledged by the European Commission as a promising approach to promote entrepreneurship, creativity and innovation skills [17].

\section{CONCLUSION}

New Finnish National Core Curriculum for Basic Education has been prepared as a totally separate process from the Turku University of Applied Sciences' Innovation Pedagogy or the FINCODA process. Additionally, these processes are targeted to different school levels. However, when speaking about the core aims, ideologies or even the methods of these different processes, there are much more consistencies than conflicts. Therefore, the way for life-longlearning in enhancing innovation capacity is already there. As presented in the new Finnish National Basic Education Curriculum, different subjects should not be any more seen as individual silos. This same approach applies to different education levels: there should be a consistent and solid path for a student from kindergarten until University.

Overall, strong institutional commitment like in TUAS added with professional support and in-service training enable all teachers to renew their role and practices to meet the requirements of Innovation Pedagogy [18]. Sustainable success can only be achieved when national and institutional strategies (defining of learning outcomes), national and institutional curricula and implementation plan and practices (teaching and learning activities) and finally national and organizational assessment practices (assessing of learning outcomes) are fully in line. We in Finland are grateful if our findings and examples inspire and encourage others to find better practices towards effective enhancement of innovation competences.

How about Indonesia? The transform from "datang, duduk, diam" learning culture towards student-centred learning and aiming at enhancing innovation competences takes time, nothing happens overnight in this theme. There is a need to arm existing and forthcoming teachers and lecturers with the capacity to plan and implement education according to prerequisites of enhancing innovation competences.

I have led now almost three years an operational called "Modernization of Indonesian Higher Education with Tested European Pedagogical Practices" and worked closely with several Indonesian Universities and seen the genuine will for modernization among Rectors, lecturers and students. Additionally, after my previous fruitful debates with the core Directors of the Indonesian Ministry for Research, Technology and Higher Education related to teachers' 
education in Indonesia - especially Prof. Intan Ahmad, Dr. Pauline Pannen and Dr. Paristiyanti Nurwardani - I'm confident that Indonesian teachers' training will face positive reforms and innovation capacity of teachers and students will be in high priority in the future.

\section{REFERENCES}

[1] World Economic Forum, "The Future of Jobs: Employment, Skills and Workforce Strategy for the Fourth Industrial Revolution”. 2016.

[2] Butter, Rene \& van Beest, Wilke, "Psychometric validation of a tool for Innovation Competencies Development and Assessment using a mixed-method design”. 2017.

[3] Biggs, John B, "Aligning Teaching for Constructing Learning". Article. 2003

[4] www.seameo.org (retrieved 20.8.2018)

[5] The Council of the European Union, "Notices from european union institutions and bodies. Council conclusions of 12 May 2009 on a strategic framework for European cooperation in education and training ('ET 2020')". 2009.

[6] Council of the European Union, "Council Recommendation on Key Competences for Lifelong Learning”. 2018.

[7] European Commission SWD(2017) 164 final, "communication from the commission to the european parliament, the council, the european economic and social committee and the committee of the regions on a renewed EU agenda for higher education”. 2017.

[8] Lehto, A \& Penttilä, T (eds), "Pedagogical Views on Innovation Competences and Entrepreneurship". 2013.
[9] Sahlberg, Pasi, Finnish Lessons; "What Can the World Learn from Educational Change in Finland". 2011.

[10] https://www.youtube.com/watch? $=z D Z F c D G p L 4 U$ (retrieved 21.8.2018)

[11] OECD, "TALIS 2013 Results. An International Perspective on Teaching and Learning". 2014.

[12] Finnish National Agency for Education, "Finnish National Core Curriculum for Basic Education”. 2014.

[13] http://www.kivaprogram.net/ (retrieved 21.8.2018)

[14] Juha Kettunen, Liisa Kairisto-Mertanen, Taru Penttilä, "Innovation pedagogy and desired learning outcomes in higher education". On the Horizon Vol: 21, Issue: 4, 2013, pp.333 - 342.

[15] Keinänen, M., Ursin, J., \& Nissinen, K., "How to measure students' innovation competences in higher education: Evaluation of an assessment tool in authentic learning environments, Studies in Educational Evaluation", Vol. 58, 2018, pp. 30-36.

[16] www.fincoda.eu (retrieved 20.8.2018)

[17] European Commission $\operatorname{COM}(2017) 247$ final, "commission staff working document. Accompanying the document Communication from the Commission to the European Parliament, the Council, the European Economic and Social Committee and the Committee of the Regions on a renewed EU agenda for higher education". 2017.

[18] Kairisto-Mertanen, Liisa; Räsänen, Meiju; Lehtonen, Jouko; Lappalainen, Harri, "Innovation Pedagogy - Learning Through Active Multidisciplinary Methods". 2012. 